\title{
LA ISLA ANTROPOFÁGICA
}

Gabriel Moreira Faulhaber *

(iD) https://orcid.org/0000-0002-7779-1256

Como citar este artigo: FAULHABER, G. M. La isla antropofágica. Todas as Letras Revista de Lingua e Literatura, São Paulo, v. 22, n. 3, p. 1-11, set./dez. 2020. DOI 10.5935/1980-6914/eLETLT2011743

Submissão: agosto de 2018. Aceite: julho de 2020.

Resumo: O presente trabalho consiste em relacionar as intuições e propostas feitas por Oswald de Andrade em seus manifestos - "Manifesto da Poesia Pau-Brasil" (1924) e "Manifesto Antropófago" (1928) - com os principais aspectos assinalados por Antonio Benitez Rojo em La isla que se repite (1998).

Palavras-chave: Antropofagia. Caribe. Pluralidade. Modernismo. Vanguarda. 


\section{Alguma antropofagia}

O início do século XX é marcado pelo surgimento das vanguardas europeias: dadaísmo, surrealismo, cubismo etc. Cada uma delas surge apresentando traços bem específicos. No entanto, na busca por um máximo distanciamento relativo às tradições e convenções do passado e seguindo uma onda de invasão por parte do chamado exotismo etnográfico em museus e ateliês, cada vanguarda, a seu modo, demonstra uma inclinação em adotar o primitivismo como sua temática, já "que faz parte das regras do jogo dos grupos aos quais se atribuiu tal designação de provocar o choque em seus leitores ou espectadores" (ROUANET, 2011, p. 171).

Dentro de tal cenário, o modernismo brasileiro, também a seu modo, sem reeditar diretamente nenhuma daquelas formas, não passa indiferente, ao ter o primitivismo como um tema central em seus principais manifestos, especificamente o Pau-Brasil e o Antropófago. Pode-se dizer que o nosso modernismo, especialmente com a figura de Oswald de Andrade, significa uma espécie de conexão - uma vez que nunca foi negada a influência externa - e, ao mesmo tempo, diferença - dada sua potência inventiva - em relação às vanguardas citadas.

Para Oswald de Andrade, sobretudo, era o primitivismo que nos capacitaria a encontrar nas descobertas e formulações artísticas do estrangeiro aquele misto de ingenuidade e pureza, de rebeldia instintiva e elaboração mítica que formavam o depósito psicológico e ético da cultura brasileira (NUNES, 1979, p. 25).

Lançado em 1924, o "Manifesto da Poesia Pau-Brasil" apresenta como grande proposta a criação de uma poesia de exportação que, em vez de influenciada, passaria a influenciadora, calcada em uma conciliação da cultura nativa com uma cultura intelectual renovada. Para seguir tal caminho, temos a proposição de um híbrido, composto pela escola e a floresta. Temos a base dupla e presente - a floresta e a escola. A raça crédula e dualista e a geometria, a álgebra e a química, logo depois da mamadeira e do chá de erva-doce. Um misto de "dorme nenê que o bicho vem pegar" e de equações (ANDRADE, 2011b, p. 65).

Oswald aponta para uma harmonia resultante de um encontro entre a cultura nativa e a cultura intelectual, ou seja, um composto híbrido, um ajuste procedente da assimilação entre uma e outra. Vemos que ele "reconhece uma situação cultural tensionada, dela tirando partido" (GOMES, 2011, p. 415), na tentativa de resolução do impasse dessas diferentes heranças.

Além disso, entre exaltações ataques, o Manifesto se constitui como "um caleidoscópio de intenções e intuições" (SILVA, 2009, p. 39). Do lado das exaltações, temos como mote a originalidade nativa e sua capacidade de ver com olhos livres, simbolizando não uma visão ingênua, mas um imperativo para que nossa visão liberte-se de categorias centralizadoras não satisfatórias e busque uma interpretação da realidade brasileira de forma que possamos dar conta de nossas contradições. "O contrapeso da originalidade nativa para inutilizar a adesão acadêmica” (ANDRADE, 2011b, p. 66). De outro lado, como principais alvos dos referidos ataques, aparecem a igreja católica, a gramática oficial, o discurso histórico, o bacharelismo, entre outros. "O lado doutor. Fatalidade do primeiro branco aportado e dominando politicamente as selvas selvagens. O bacharel" (ANDRADE, 2011b, p. 60).

Percebemos no Manifesto de 1924 um projeto para uma grande mudança tanto no pensamento quanto na produção literária brasileira -, calcada em uma 
reeducação da sensibilidade, em "uma sensibilidade reajustada" (NUNES, 2011, p. 18). Assim, pode-se encontrar no "Manifesto da Poesia Pau-Brasil" aspectos que, de certa forma, serão intensificados no "Manifesto Antropófago". Em resumo, pode-se encontrar a Antropofagia em estado embrionário. Como nos diz Haroldo de Campos (1976, p. 57): "para o olho crítico estes dois textos oswaldianos formam uma peça única, o segundo contido fundamentalmente no primeiro".

Por sua vez, em 1928, por meio do "Manifesto Antropófago", a Antropofagia surge como pensamento que tem como influência a prática dos indios tupis, na qual o ato de devorar o outro era acompanhado da absorção de suas qualidades. Oswald transporta essa prática para o âmbito cultural com a proposta de reabilitar o homem primitivo que, por meio de uma operação antropofágica, é capaz de devorar a cultura do outro e transformá-la em própria, compreendendo o outro como algo que deva ser incorporado e não combatido, ou ignorado. Ao dizer: "só me interessa o que não é meu" (ANDRADE, 2011a, p. 67), aponta para a "constituição de um eu-brasileiro produzido na devoração de toda e qualquer alteridade" (ALMEIDA, 2002, p. 67).

Vale ressaltar que o que temos não é a retratação do antropófago tal como foi, mas sim uma reinvenção de um antropófago. "Marcadamente diferenciado do modelo romântico, indio configurado por Oswald de Andrade, tampouco se assemelhava ao seu modelo real" (GOMES, 2010, p. 43). Foi apresentado um índio que não estava na história, "uma subversão da história oficial" (SILVA, 2009, p. 48). Oswald inventou, criou um índio.

Ao lermos o Manifesto, vemos que ele é carregado de um tom agressivo, provocador e zombeteiro, disparando contra a ordem, a sociedade, a cultura e a história brasileira até então instituídas, em nome de uma rebelião do homem natural. Marcado pelo humor, apresenta-se como um diagnóstico e como um tratamento (NUNES, 2011), convidando a "intelligentsia brasileira a repensar o modo de relação com o antigo colonizador" (NASCIMENTO, 2011, p. 334). Como diagnóstico, aponta a sociedade brasileira como vítima de um trauma, ocasionado pela repressão colonizadora. Como tratamento, propõe uma reação, uma rebeldia contra os tabus visando à realização de um desrecalque cultural, em busca de uma "realidade sem complexos, sem loucuras, sem prostituições e sem penitenciarias do matriarcado de Pindorama" (ANDRADE, 2011a, p. 74). Nesse ato de rebeldia, os alvos são as instâncias do domínio europeu, geradoras do nosso recalque, e as armas são nossos símbolos míticos. De um lado, Vieira e Anchieta. De outro, Guaraci e Jaci. Temos um ataque, uma projeção destes sobre aqueles. De forma que, na operação antropofágica, pregada por um dos seus mais famosos ditos, "a transformação permanente do tabu em totem" (ANDRADE, 2011a, p. 69), tenhamos o desrecalque.

Assim se delineia o "Manifesto Antropófago": avaliando "os estragos de uma nação que se perdera em modelos culturais impostos” (GOMES, 2010, p. 47) e buscando superar os problemas causados pela presença repressora do colonizador. Deixemos Oswald falar:

Queremos a Revolução Caraíba. Maior que a Revolução Francesa. A unificação de todas as revoltas eficazes na direção do homem. Sem nós a Europa não teria sequer sua pobre declaração dos direitos do homem [...] Contra o Padre Vieira, autor de nosso primeiro empréstimo, para ganhar comissão. O rei analfabeto dissera-lhe: ponha isso no papel, mas sem muita lábia. Fez o empréstimo. 
Gravou-se o açúcar brasileiro. Vieira deixou o dinheiro em Portugal e nos trouxe a lábia (ANDRADE, $2011 \mathrm{a}$, p. 68-69).

Oswald inverte o ângulo de visão, modificando o curso das influências e condicionando a nós, povos do novo mundo, papel decisivo e central nas transformações ocorridas em todo o planeta. Com esse golpe, a revolução caraíba se torna maior que todas as revoluções, "a vanguarda de todas as vanguardas" (NUNES, 1979 , p. 35). Assim, trabalhando com uma revisão do mundo não europeu, desconstruindo a história dada, reivindica o direito de narrarmos nossa própria história e construirmos nossas próprias imagens. Em vez de sermos falados, adquirimos voz ${ }^{1}$. De objeto do enunciado, passamos a sujeito da enunciação. Com isso, "Oswald propõe desinverter o que ficara invertido com a chegada do português" (GREENE, 2011, p. 214). Uma vez que: "antes dos portugueses descobrirem o Brasil, o Brasil já tinha descoberto a felicidade" (ANDRADE, 2011a, p. 72). Partindo disso, seriamos uma espécie de utopia realizada. Tudo que a Europa estaria procurando, já teríamos aqui. "Já tínhamos o comunismo. Já tínhamos a língua surrealista. A idade de ouro" (ANDRADE, 2011a, p. 70). Todo esse processo nos habilita a ser o motor em direção ao Matriarcado de Pindorama.

Apontado como traço característico dos textos oswaldianos, chegando ser difícil a separação entre o sério e o irônico em suas obras, o humor também aparece com sua força no "Manifesto Antropófago". Seguindo seu estilo, Oswald contamina o Manifesto por meio de brilhantes ditos cômicos. "Fizemos Cristo nascer na Bahia. Ou em Belém do Pará" (ANDRADE, 2011a, p. 69). Dentro dessa postura, "na antropofagia, Freud é brasileiro e a utopia já foi alcançada. No caldeirão, tabus foram transformados em totens pela alegria e a felicidade do saber primitivo e local" (JACKSON, 2011, p. 436). Ou seja, o humor também funciona como uma ferramenta de inversão do ângulo de visão e contribuindo como tratamento para o diagnóstico dado.

Deve-se entender a Antropofagia não como um mero processo de colagem ou uma assimilação indiscriminada; "antropofagia nada tem a ver com a frouxidão do ecletismo, com a indistinção do gosto alimentar" (MONTEIRO, 2010, p. 118), mas como um processo criterioso que necessita de um rigor com o qual se escuta e afirma a alteridade. Dessa forma, "o critério de seleção para o ritual antropofágico na cultura não é o conteúdo do sistema de valor em si, mas o quanto funciona e com o que funciona, o quanto permite passar intensidades e produzir sentido" (ROLNIK, 1998, p. 6). Ou seja, a Antropofagia não se configura como uma questão sobre o que devorar, mas o como e o porquê devorar.

Ultrapassando seu tempo, podemos dizer que a Antropofagia foi responsável "por transportar para o campo das ideias politicas e sociais o espírito de insurreição artística do modernismo" (NUNES, 2011, p. 383), buscando um processo de renovação da vida tanto no aspecto individual como no social. Tudo em busca da felicidade e do equilíbrio.

Para finalizar, deixamos claro que o objetivo aqui foi um pequeno panorama, uma curta exposição dos manifestos. Cientes da dificuldade e sabendo que "a antropofagia é irredutivel a um simples objeto oferecido à análise e ao conheci-

\footnotetext{
"Um dos grandes lemas do manifesto: 'tupy or not tupy, that is the question', é em si um ato de canibalização que representa a dúvida shakespeariana no plano de um sujeito antropófago, que agora é dono de sua própria história" (SCHWARTZ, 2011, p. 255-256).
} 
mento" (NASCIMENTO, 2011, p. 334), tentaram-se extrair, ao menos, pontos-chave que estruturam o rico texto de Oswald. Dito isso, encerramos com Benedito Nunes (2011, p. 23), que nos diz: "nenhuma exposição do conteúdo do 'Manifesto Antropófago', que é o avesso do discurso lógico, pode compensar a falta das imagens e dos trocadilhos que nos dá seu texto, cheio de intuições penetrantes".

\section{CONHECENDo LA ISLA gUE SE REPITE}

Em La isla que se repite, Benítez Rojo, não intentando fazer uma história, mas assinalando processos econômicos e sociais da formação do arquipélago, nos traz uma leitura particular do Caribe ao apresentar traços extremamente singulares nele presentes. Entre outras questões, o autor parte da ideia de meta-arquipélago, uma região que carece de limites e centro, para apontar para a presença de um mesmo passado comum, marcado pela violência colonizadora do sistema de escravidão e da plantation. Tais fatos disparariam um feixe de heterogeneidade e diferenças que estruturam a singularidade de uma área cultural e que extrapola as noções de unidade linguística, territorial e nação. Dessa forma, "temos um Caribe amplo que se repete de forma diferente em cada ilha, em cada setor do continente americano, também estendido como parte deste meta-arquipélago" (REIS, 2010, p. 95).

Trabalhando dentro dessa união do diverso, na qual surgem regularidades que se repetem, tendo o ritmo, a música e a dança como marcas comuns, Benítez Rojo (1998, p. 17) tende a focar-se nas manifestações dinâmicas "dentro de lo marginal, lo residual, lo incoherente, lo heterogéneo o, si se quiere, lo impredecible que coexiste com nos ostros en el mundo de cada dia ${ }^{2}$. Estamos diante de uma área extremamente complexa de povos atravessados por transculturações, sincretismos e crioulizações. Para ilustrar seu pensamento sobre a região e reforçar sua ideia de meta-arquipélago, o autor evoca a imagem da Via Láctea:

[...] si alguien exigieria uma explicación visual, una gráfica de que es el Caribe, lo remitiria al caos espiral de la Via Láctea, el impredecible flujo de plasma transformativo que gira com parsimonia em la bóveda de nuestro globo, que dibuja sobre este um contorno "outro" que se modifica a sí mesmo cada instante, objetos que nascem a la luz mientra otros desaparecen en lo seno delas sombras; cambio, tránsito, retorno, flujos de matéria estelar ${ }^{3}$ (ROJO, 1998, p. 18).

Vemos que se trata de um mundo de encontros e produções, um lugar sem centro e sem limites, "resultado do maior entrelaçamento e fusão, na fornalha da sociedade colonial, de diferentes elementos culturais africanos, asiáticos e europeus" (HALL, 2003, p. 31). Deve-se destacar a forte presença do negro, promovendo uma africanização da cultura, com influências que encontram ressonâncias em suas mais diversas produções. Tudo isso resulta no que o autor denomina "los Pueblos Del mar" que "se repitem incesantemente diferenciándose

\footnotetext{
"dentro do marginal, do residual, do incoerente, do heterogêneo ou, se você preferir, do imprevisível que convive conosco no mundo de cada dia" (ROJO, 1998, p. 18, tradução nossa).

3 "se alguém exigisse uma explicação visual, um gráfico do que é o Caribe, isso o remeteria ao caos espiral da Via Láctea, o fluxo imprevisível de plasma transformador que gira lentamente na cúpula de nosso globo, que desenha neste contorno 'outro' que se modifica a cada momento, objetos que nascem na luz enquanto outros desaparecem no seio das sombras; mudança, trânsito, retorno, fluxos de materiais estelares" (ROJO, 1998, p. 18, tradução nossa).
} 
entre sí, viajando juntos hasta el infinito" (ROJO, 1998, p. 32). Percebemos uma cultura aquática, dotada de processos assimétricos como as ondas e as correntes marinhas e suas sinuosidades e irregularidades.

Dentro desse emaranhado sem centro e sem borda, encontramos formas potentes de discursos - literatura, música, dança - com ritmos e dicções únicos. Detentores e provedores de possibilidades que não param de se desdobrar, tais discursos surgem como um antídoto, visando neutralizar a violência no interior de uma região que nasceu "dentro da violência e através dela" (HALL, 2003, p. 30). Nos dizeres de Benítez Rojo (1998, p. 32-33):

[...] cada uno destos ritmos es, a su vez, un flujo que es cortado por otros ritmos, y asi podemos seguir de fujos a ritmos hasta deternos donde queramos. Bien, la cultura de los Pueblos del Mar es um flujo cortado por ritmos que intentan silenciar los ruidos com que su propia forma social interrumpe el discurso de la natureza. Si esta definición resultara abstrusa, podríamos simplifircala diciendo que el discurso cultural de los Pueblos del Mar intenta, a través de un sacrificio real o simbólico, neutralizar la violência y remitir al grupo social a los códigos trans-históricos de la natureza [..] la cultura de los Pueblos del Mar expresa el desejo de conjurar la violência social remitiedose a um espaço que solo pode ser intuído a através de lo poético, puesto que siempre presenta uma zona de $\operatorname{caos}^{5}$ (ROJO, 1998, p. 32-33).

Temos um processo curativo de teor quase místico, baseado em estruturas poéticas que não podem ser facilmente traduzidas através de mecanismos convencionais. Essas estruturas possuem dinâmicas e fluxos próprios que atuam em resistência à violência, proporcionando deslocamentos para outros espaços nos quais os ritmos possam atuar em movimentos de redemoinho em direção a uma dicção poética da não repressão.

Isso nos lembra Paul Gilroy (2001), que em O Atlântico negro nos diz que a região é um lugar fractal e rizomórfico, com todo o potencial de contribuir para a saúde do nosso planeta. Em nosso entender, essa contribuição vem justamente desse não engessamento, dessas possibilidades de vida não codificadas, construídas a partir de e com esses processos descentralizadores, de intensa fuga e diferenciação.

Nesses aspectos, a literatura adquire contornos especiais, gerando textos e linguagens plurais, em constante transformação.

Asi, el texto caribñeo es excesivo, denso, uncanny, asimétrico, entrópico, hermético, pues, a manerae um zoológico o bestiário, abren sus puertas a dos grandes órdenes de lectura: una orden secundário, epistemológica, profana, diurna y referida a Ocidente - al mundo de afuera -, donde el texto se desenrosca y se agita como um animal fabuloso para ser de conecimiento y desejo; outra de orden principal, teleológica, ritual, nocturna y revertida al próprio Caribe, donde

4 "repetem incessantemente, diferenciando-se entre si, viajando juntos até o infinito" (ROJO, 1998, p. 32, tradução nossa).

5 "cada um desses ritmos é, por sua vez, um fluxo que é interrompido por outros ritmos e, portanto, podemos pular de fluxos em ritmos até parar onde quisermos. Pois bem, a cultura dos Povos do Mar é um fluxo cortado por ritmos que tentam silenciar os ruídos à medida que a sua própria forma social interrompe o discurso da natureza. Se esta definição se revelar confusa, poderíamos simplificá-la dizendo que o discurso cultural dos Povos do Mar tenta, por meio de um sacrifício real ou simbólico, neutralizar a violência e remeter o grupo social aos códigos trans-históricos da natureza [..] A cultura dos Povos do Mar expressa o desejo de repelir a violência social referindo-se a um espaço que só se intui através da poética, pois sempre apresenta uma zona de caos" (ROJO, 1998, p. 32-33, tradução nossa). 
el texto despliega su monstruosidad bisexual de esfinge hacia el vácuo de su impossible origen, y sueña que lo incorpora y que es incorporado por este ${ }^{6}$ (ROJO, 1998, p. 39).

Estamos diante de um texto de significantes móveis, uma máquina de significados, que incessantemente escapa das forças redutoras e nos guia para outros rumos, sem destino final e em constante processo. Trata-se de um texto capaz de nos conduzir através de instabilidades em direção ao imprevisto e ao improvável, atuando em resistência às forças homogeneizantes, contra o fechamento e contribuindo para outras formas de percepção.

Las apropriciones y transculturaciones de los diversos contactos (caribeños autóctonos, europeos, africanos, asiáticos y orientales) que hubo em esa región originaron no solo um lenguaje, sino una manera distinta de sentir el mundo [...] Esta manera de entender lo caribeño permitiria ver la movilidad de una cultura - otra que no niega sus multiples influencias y por lo tanto aún está abierta a nuevos câmbios ${ }^{7}$ (MIRANDA, 2005, p. 28).

Outra vez temos ressaltado o poder e a plasticidade de se extrair, a partir desses encontros-experiências que atravessam esses povos, produções que não podem ser medidas por padrões estabelecidos. Assim, impedindo a estabilização com seus processos de desarticulação e rearticulação em constantes deslizes, surgem modos de viver, sentir e pensar como formas de resistência responsáveis por práticas estéticas específicas. Nesse sentido, o que encontramos são produções que mobilizam, modificam e estimulam as mais diversas formas de recepção e análise.

Antes de entrarmos em nossa proposta de leitura comparativa, deixamos mais uma passagem de La isla que si repite com o intuito de reforçar os apontamentos de Benítez Rojo (1998, p. 16): “el espectro de lo códigos caribeños resulta de tal abigarramento y densidad que informa la región como una espesa sopa de signos, fuera de del alcance de cualquier disciplina em particular y cualquier invertigador individual ${ }^{8}$ ".

\section{LA ISLA ANTROPOFÁGICA}

Ao longo da seção anterior, insistimos no caráter deslizante, na plasticidade, na descontinuidade e na resistência dos modos de ser, sentir, pensar presentes na região avaliada por Benítez Rojo. É justamente esse traço que mais aproxima as proposições e intuições oswaldianas da leitura do autor cubano.

Como vimos, Oswald de Andrade trabalha o par Pau-brasil/Antropofagia no sentido de dar conta de nossa complexidade, fazendo um diagnóstico e propondo

6 "Assim, o texto caribenho é excessivo, denso, misterioso, assimétrico, entrópico, hermético, pois, de forma zoológica ou bestiária, abre suas portas a duas grandes ordens de leitura: uma secundária, epistemológica, profana, diurna e referente ao Ocidente para o mundo exterior -, onde o texto se desenrola e se agita como um animal fabuloso por ser de conhecimento e desejo; outra de ordem principal, teleológica, ritual, noturna e revertida ao próprio Caribe, em que o texto desdobra sua monstruosidade de esfinge bissexual para o vazio de sua origem impossível, e sonha que a incorpora e que por ela está incorporada" (ROJO, 1998, p. 39, tradução nossa).

7 "As apropriações e as transculturações dos vários contatos (autóctones caribenhos, europeus, africanos, asiáticos e orientais) que existiram naquela região originaram não só uma língua, mas uma forma diferente de sentir o mundo [...] Esta forma de entender o Caribe permitiria ver a mobilidade de uma cultura - outra que não nega as suas múltiplas influências e, portanto, ainda está aberta a novas mudanças" (MIRANDA, 2005, p. 28, tradução nossa)

8 "o espectro dos códigos caribenhos resulta de tal variedade e densidade que informa a região como uma espessa sopa de signos, fora do alcance de qualquer disciplina particular e de qualquer investidor individual" (ROJO, 1998, p. 16, tradução nossa). 
um tratamento. É nesse espaço que se situa nossa capacidade de "assimilar sob a espécie brasileira a experiência estrangeira e reinventá-la em termos nossos, com qualidades locais ineludiveis que davam ao produto resultante um caráter autônomo" (CAMPOS, 1976, p. 35). Nesse aspecto, estaríamos sob uma atmosfera de constantes encontros e processos, que "no lugar das polarizações disjuntivas, propõe uma sintese dialética" (FIGUEIREDO, 2011, p. 394). Ou seja, chega "elegendo o híbrido em detrimento das categorias puras e excludentes" (FIGUEIREDO, 2011, p. 389).

Seguindo essas linhas, Benitez Rojo (1998, p. 37) nos explica: "En realidad podría decirse que em el Caribe lo 'extranjero'. interactúa com lo 'tradicional' como um rayo de luz con um prisma; esto es; se producen fenómenos de reflexión, refración y decomposición ${ }^{9 "}$. Vemos que um filtro semelhante ao antropofágico tem sua função ativada de forma que "los procesos sincréticos se realizan a través de uma economía en cuya modalidad de intercambio el significante de allá - del Otro - es consumido (leído) conforme a códigos locales, ya preexistentes, esto es, códigos de acá10" (ROJO, 1998, p. 36).

Através desse processo de assimilação, repúdio e superação, conquista-se uma autonomia que, assumindo uma postura rebelde, torna-se não domesticável, errante, para além de codificações e catalogações, configurando-se como produtora de incessantes possibilidades, uma máquina de significados que age "pela invenção e pela surpresa" (ANDRADE, 2011b, p. 63). As práticas dela resultantes ficam assim soltas, longe de visões centralizadoras e generalizadoras, distantes de fatores que insistem em fixá-las e determiná-las a priori.

A nossa base dupla - a escola e a floresta -, responsável por uma nova educação da sensibilidade, do ver com olhos livres, atuando "contra todas as indigestões de sabedoria. O melhor da nossa tradição lírica. O melhor de nossa demonstração moderna" (ANDRADE, 2011b, p. 66), também aparece nesse Caribe, cumprindo uma função similar à anterior: subvertendo os moldes tradicionais de experiência e pensamento, autenticando modos singulares de concepção do mundo - "uma visão de mundo não excludente" (FIGUEIREDO, 2011, p. 394). Encontramos, nesse sentido, a já mencionada união do diverso, que promove "un espacio donde las ciencias puras se conectan com las ciencias sociales, y ambas com el arte y la tradición cultural ${ }^{11 "}$ (ROJO, 1998, p. 17).

O fator terapêutico dos ritmos e da dicção poética dos povos caribenhos também entra nessa relação de similaridade com a Antropofagia. Lembramos que uma das buscas oswaldianas é pelo desrecalque cultural, agindo contra as instâncias das forças dominantes e repressoras através de projeções de nossos símbolos míticos. Já no Caribe, esse fator de cura, a resistência à violência, age tendo por base uma experiência estética que "ocurre en el marco de rituales y representaciones de carácter colectivo, ahistórico e improvisatorio ${ }^{12}$ " (ROJO, 1998, p. 37). Semelhante à Antropofagia, vemos um procedimento de canalização da repressão por meio da coexistência crítica de vozes plurais produzindo um

\footnotetext{
9 "Na realidade, pode-se dizer que no Caribe o 'estrangeiro' interage com o 'tradicional' como um feixe de luz com um prisma; isto é; ocorrem fenômenos de reflexão, refração e decomposição (ROJO, 1998, p. 36, tradução nossa).

10 "os processos sincréticos se realizam por meio de uma economia na qual o significante de lá - do Outro - é consumido (lido) segundo códigos locais, já existentes, isto é, códigos daqui (ROJO, 1998, p.36, tradução nossa).

11 "um espaço onde as ciências puras se conectam com as ciências sociais, e ambas com a arte e tradição cultural" (ROJO, 1998, p. 37, tradução nossa).

12 "ocorre no quadro de rituais e representações de natureza coletiva, a-histórica e improvisatória" (ROJO, 1998, p. 37, tradução nossa).
} 
flujo poético y vital navegando por Eros y Dionisio, por Ochún y Elegua, por la Gran Madre Arahuaca y la Virgen de la Caridad de Cobre, todos ellos canalizando violência, violência essencial y ciega con que chocan las dinámicas sociales caribeñas ${ }^{13}$ (ROJO, 1998, p. 39).

O trabalho pela não captura, a não codificação, pelo deslize e pela transformação, sabendo que "deslocar e transfigurar são os movimentos básicos da antropofagia como operação cultural” (SILVA, 2009, p. 138) é outro aspecto evidenciado por Benítez Rojo. Como já apontamos, as diferentes formas de expressão presentes na região comportam-se mediante procedimentos de fuga e diferenciação, dentro de uma dinâmica particular "como es el mar, el viento y las nubes ${ }^{14 ”}$ (ROJO, 1998, p. 26). Nosso objetivo aqui, a partir das características assinaladas em Benitez Rojo, foi deixar claras as relações existentes entre as forças que transitam e atuam e se fazem agir por essa área cultural - "su condición de flujo, su difusa sensualidad, su fuerza generativa, su capacidade nutrir $^{15 "}$ (ROJO, 1998, p. 46) - com aspectos que atravessam o pensamento de Oswald de Andrade.

\section{CONSIDERAÇões FINAIS}

Buscamos neste trabalho apresentar, por meio de uma leitura comparativa, as similaridades entre o pensamento de Oswald de Andrade e as explanações feitas por Benítez Rojo acerca do Caribe e suas formas de expressão. Não se pretendeu estabelecer uma relação direta entre essas instâncias, como se a segunda fosse uma consequência lógica da primeira. Nosso intuito foi demonstrar, tendo como base as imagens e avaliações de La isla que se repite, a força e a amplitude da Antropofagia, que pode ser lida e reconhecida em outros contextos que não se restringem ao cenário de sua elaboração.

\section{ThE ANTHROPOPHAGIC ISLAND}

Abstract: This work aims to list the intuitions and propolsals maded by Oswald de Andrade in his manifests - "Manifesto da Poesia Pau Brasil" (1924) e "Manifesto Antropófago" (1928) - with main aspects highlighted by Antonio Benítez Rojo em La isla que se repite (1998).

Keywords: Anthropophagy. Caribbean. Plurality. Modernism. Vanguard.

\section{REFERÊNCLAS}

ALMEIDA, M. C. F. de. Tornar-se outro. O topos canibal na literatura brasileira. São Paulo: Annablume, 2002.

ANDRADE, O. de. Manifesto Antropófago. In: ANDRADE, O. de. A utopia antropofágica. São Paulo: Globo, 2011a.

\footnotetext{
13 "fluxo poético e vital navegando por Eros e Dionisio, por Ochún e Elegua, pela Grande Mãe Arahuaca e pela Virgen de la Caridad de Cobre, todos eles canalizando a violência, violência essencial e cega com que se chocam as dinâmicas sociais caribenhas" (ROJO, 1998, p. 39, tradução nossa).

14 "como é o mar, o vento e as nuvens" (ROJO, 1998, p. 26, tradução nossa).

15 "sua condição de fluxo, sua sensualidade difusa, sua força geradora, sua capacidade de nutrir" (ROJO, 1998, p. 46, tradução nossa).
} 
ANDRADE, O. de Manifesto da Poesia Pau-Brasil. In: ANDRADE, O. de. A utopia antropofágica. São Paulo: Globo, 2011b.

CAMPOS, H. Uma poética da radicalidade. In: ANDRADE, O. de. Poesias reunidas. São Paulo: Civilização Brasileira, 1976.

FIGUEIREDO, V. F. de. Antropofagia: uma releitura do paradigma da razão moderna. In: ROCHA, J. C. de C.; RUFFINELLI, J. (org.). Antropofagia hoje? Oswald de Andrade em cena. São Paulo: É Realizações, 2011.

GILROY, P. O Atlântico negro. São Paulo: Editora 34, 2001.

GOMES, H. T. A questão racial na gestação da antropofagia oswaldiana. In: ROCHA, J. C. de C.; RUFFINELLI, J. (org). Antropofagia hoje? Oswald de Andrade em cena. São Paulo: É Realizações, 2011.

GOMES, H. T. Antropofagia. In: FIGUEIREDO, E. (org.). Conceitos de literatura e cultura. Juiz de Fora: Ed. UFJF, 2010.

GREENE, R. Antropofagia, invenção e a objetificação do Brasil. In: ROCHA, J. C. de C. RUFFINELLI, J. (org.). Antropofagia hoje? Oswald de Andrade em cena. São Paulo: É Realizações, 2011.

HALL, S. Da diáspora: identidades e mediações culturais. Belo Horizonte: UFMG, 2003.

JACKSON, K. D. Novas receitas da cozinha canibal. In: ROCHA, J. C. de C.; RUFFINELLI, J. (org.). Antropofagia hoje? Oswald de Andrade em cena. São Paulo: É Realizações, 2011.

MIRANDA, F. Hacia uma narrativa afroecuatoriana: cimarronaje cultural en América Latina. Quito: Ediciones Abya-Yala, 2005.

MONTEIRO, A. O pensamento antropofágico e a experiência da subjetividade. In: NASCIF, R. M. A.; LAGE, V. L. C. (org). Literatura, critica e cultura IV: interdisciplinaridade. Juiz de Fora: Ed. UFJF, 2010.

NASCIMENTO, E. A antropofagia em questão. In: ROCHA, J. C. de C.; RUFFINELLI, J. (org.). Antropofagia hoje? Oswald de Andrade em cena. São Paulo: É Realizações, 2011.

NUNES, B. Antropofagia ao alcance de todos. In: ANDRADE, O. de. A utopia antropofágica. São Paulo: Globo, 2011.

NUNES, B. Antropofagia e vanguarda - acerca do canibalismo literário. In: NUNES, B. Oswald canibal. São Paulo: Perspectiva, 1979.

REIS, L. O Haiti é aqui, o mar sem fronteiras. In: CARRIZO, S. L.; NORONHA, J. M. G. (org.). Relações literárias interamericanas: território \& cultura. Juiz de Fora: UFJF, 2010.

ROJO, A. B. La isla que se repite. Barcelona: Casiopea, 1998.

ROLNIK, S. Subjetividade antropofágica. In: HERKENHOFF, P.; PEDROSA, A. (ed.). Arte contemporânea brasileira: um e/entre outro/s: XXIV Bienal Internacional de São Paulo. São Paulo: Fundação Bienal de São Paulo, 1998. p. 128-147. Disponivel em: http://www.pucsp.br/nucleodesubjetividade/Textos/SUELY/ Subjantropof.pdf. Acesso em: 19 ago. 2018.

ROUANET, M. H. Quando os bárbaros somos nós. In: ROCHA, J. C. de C.; RUFFINELLI, J. (org.). Antropofagia hoje? Oswald de Andrade em cena. São Paulo: É Realizações, 2011. 
SCHWARTZ, J. De símios e antropófagos. Os macacos de Lugones, Vallejo e Kafka. In: ROCHA, J. C. de C.; RUFFINELLI, J. (org.). Antropofagia hoje? Oswald de Andrade em cena. São Paulo: É Realizações, 2011.

SILVA, A. P. da. Mário e Oswald: uma história privada do modernismo. Rio de Janeiro: 7letras, 2009. 